\title{
Les Houches Summer School
}

\section{DeWitt}

In trying to write a brief history of the Summer School for Theoretical Physics at Les Houches, I find myself facing an impossible task. On the one hand, the neutral tone of an administrative report such as: "On 18 April 1951 the Council of the University of Grenoble decided to create a Summer School of Theoretical Physics..." is not appropriate when addressing the members of the European Physical Society, who are not an impersonal institution, but a group of friends desirous of strengthening their mutual relationships, and among whom many have made personal contributions to the Summer School. On the other hand, the history of the School at a human level cannot be fully told without infringing on the privacy of its friends, nor can it be told in a few columns without ignoring many of its facets.

During the years following the Second World War, a French student who wished to start research in physics after graduation from university found a gap separating him from the world of research. Original publications were intelligible to experts only, and the novice found it difficult by himself to acquire quickly the basic knowledge necessary for comprehension. It was not easy for him to find a guide to direct him through the maze of research. If he sensed the importance of the work being done in certain laboratories and wished to acquire first-hand knowledge of it, he did not know how to establish the contacts which would open the doors of the laboratories to him. When I was a student, my attention had been drawn by Letort to a mysterious Mécanique Ondulatoire; in trying to find out what this was, I had the good fortune, thanks to Joliot, to go to Dublin where Heitler, Peng and Schrödinger did not hesitate to take somebody completely green into their hands, then to Copenhagen and Princeton, and I began to perceive a wealth too intriguing not to be shared.

A summer school would permit physicists and would-be physicists to meet specialists from all over the world during the university recess, and to hear the authors of recent developments in physics discuss these developments in their technical details and within the general framework of modern physics. Choosing a setting in the mountains would provide, in a stimulating climate, the peaceful atmosphere needed for intensive intellectual work.

One can find in a report which is available at the School's Secretariat - Ecole d'Eté de Physique Théorique, 74 Les Houches, France - a description of the School's activities since 1951, of its organization, a list of the countries and organizations which have subsidized it, a list of lectures, participants, publications and indications of the activities which have originated at Les Houches. In addition, one can find the admission requirements.

These lists mention that Pauli came every year, that Fermi was present in 1954, that some professors came again later as students, and vice versa, etc. ... They do not say that, aside from his lectures, Pauli participated closely in the elaboration of programmes to be sure that we would not float in a vacuum, but would tackle the real problems. They do not mention that, in spite of the illness that he was beginning to feel, Fermi gave all his time and attention to those who wished to continue the discussions started during his lectures. They cannot describe the role that the sessions played for each participant, the turn taken for some of them in their scientific career; nor do they tell of the role that the School played in creating other summer schools. Perhaps, in order to discern the original character of the School, one must have lived eight weeks at Les Houches, discussed physics in the dining room at Les Balmes, in the study rooms of La Jacassière, in the meadow by the Revets, facing the Mont Blanc chain of mountains, penetrating the new problems of physics with the authors themselves.

Lack of space prevents me from mentioning all the cooperation that the School has received. However, I would like to mention the Ministere de I'Education Nationale, the Commissariat à l'Energie Atomique, the Scientific Affairs Division of NATO, la Commission Franco-Américaine d'Echanges Universitaires, l'Alcatel, the Institut Interuniversitaire des Sciences Nucléaires Belge, the Swedish Statens Rad för Atomöforskning, the Norwegian Almenvitenskapelige Forskningrad the Dutch ZWO, and the Ford Foundation, whose financial contributions have assured the existence of the School.

At the present time, when the School is preparing its twentieth session, it is good to analyze the needs of physics and to chart the course ahead. The needs during the first years were evident: basic courses in quantum mechanics and statistical mechanics, with applications in the various branches of physics. In 1958, these subjects having been firmly taken in hand by a good number of European universities, the School began to organize its sessions around a special theme in answer to requests made by interested physicists.

The rapid evolution of physics does not, indeed, allow for each university to incorporate in its curricula the most recent developments in all fields. It is difficult for the experienced physicist, burdened with responsibilities, to study those new branches which do not directly concern his immediate study, although his experience would, in principle, allow him to exploit them profitably. As a pilot institution the School can answer rapidly the needs which are brought to its attention. Thus since 1958 the sessions have covered the following topics: The Many Body Problem (1958), The Theory of Neutral and Ionized Gases (1959), Dispersion Relations and Elementary Particles (1960), Low Temperature Physics (1961), Geophysics, the 
Earth's Environment (1962), Relativity, Groups and Topology (1963), Quantum Optics and Electronics (1964), High Energy Physics (1965), High Energy Astrophysics (1966), Many Body Physics (1967), Nuclear Physics (1968), and Physical Problems in Biological Systems (1969).

After twenty years of existence, one would like to say that the difficulties encountered in the first years, involving the insertion of a new institution into the existing administrative framework, have been eliminated. Unfortunately, although many difficulties have largely been resolved, others have developed. In recent years administrative machinery has often become heavier to manoeuver. A proliferation of justifications, reports, etc. make the administration of the same grant a much more cumbersome task than twenty years ago. It is a delicate job for the beneficiaries to practice self-defence against administrative harassment when the opponent is in fact the friend who gives them money. Nevertheless, it seems to me that it is the user's duty to bring to the attention of his donor, who obviously wishes him well, certain administrative simplifications which would improve the situation - simplifications which the user conceives of better than anyone else.

After twenty years of existence, the fire continues to burn and, at present, the log which keeps it alive is as essential as the match which provided the original spark. Discretion obliges me to keep silent the name of a former student who has just given to the School the entire inheritance received from his mother. This gesture follows the tradition of the enthusiasm of the first participants, of the devotion of those who assure its development, of the intelligent comprehension of those who have to solve the many problems raised by its organization and of the generosity of its collaborators and faithful friends.
Mathematical Physics will be the subject of the 1970 session of the Ecole d'Eté de Physique théorique, an Institute of the University of Grenoble. The session will be held at Les Houches (Haute Savoie), France, from 5 July to 29 August. This session is supported in part by the NATO Advanced Study Institute Programme. The course is intended for both young researchers working in Mathematical Physics and for experienced theoreticians wishing to study the mathematical problems encountered in theoretical physics, using the most powerful mathematics currently available and the rigour they imply. Stress will be placed on mathematical problems of systems with an infinite number of degrees of freedom, the foundations of theories, and the study of models.

The programme is as follows :

J. Glimm (Courant Institute) and A. Jaffe (Harvard) Selected Topics in Functional Analysis

D. Ruelle (IHES)

Rigorous Results in Statistical Mechanics

Present Status of Axioms of Quantum Field Theory

E.H. Lieb (MIT)

Models in Statistical Mechanics

R. B. Griffiths (Carnegie Mellon)

Phase Transitions

K. Hepp (ETH)

Théorie générale de la Rénormalisation

J. Ginibre (Orsay)

Intégrale fonctionnelle en Mécanique statistique

The director of study will be Raymond Stora (Marseille-Luminy)

Admission will be limited to thirty five participants. Further information and application forms can be obtained from the School : Ecole d'Eté de Physique théorique, F-74 Les Houches or from Professor Cécile DeWitt, Department of Physics, University of North Carolina, Chapel Hill, North Carolina 27514, USA. Applications, including complete dossiers, must be received in Les Houches not later than 15 March. 